\title{
White Matter Abnormalities in Veterans With Mild Traumatic Brain Injury
}

\author{
Ricardo E. Jorge, M.D., Laura Acion, Ph.D., M.P.H., Tonya White, M.D., Ph.D., Diana \\ Tordesillas-Gutierrez, Ph.D., Ronald Pierson, M.S., Benedicto Crespo-Facorro, M.D., and \\ Vincent A. Magnotta, Ph.D. \\ Departments of Psychiatry and Radiology, Carver College of Medicine, University of lowa, lowa \\ City, lowa; the lowa Consortium for Substance Abuse Research and Evaluation, University of \\ lowa; the lowa City Veterans Affairs (VA) Medical Center; the Department of Child and \\ Adolescent Psychiatry and the Department of Radiology, Erasmus University Medical Centre, \\ Rotterdam, the Netherlands; the University Hospital Marqués de Valdecilla, CIBERSAM, IFIMAV, \\ and Department of Psychiatry, School of Medicine, University of Cantabria, Santander, Spain; \\ and Brain Image Analysis, LLC, Coralville, lowa
}

\begin{abstract}
Objective-It has been estimated that $10 \%-20 \%$ of U.S. veterans of the wars in Iraq and Afghanistan experienced mild traumatic brain injury (TBI), mostly secondary to blast exposure. Diffusion tensor imaging (DTI) may detect subtle white matter changes in both the acute and chronic stages of mild TBI and thus has the potential to detect white matter damage in patients with TBI. The authors used DTI to examine white matter integrity in a relatively large group of veterans with a history of mild TBI.
\end{abstract}

Method-DTI images from 72 veterans of the wars in Iraq and Afghanistan who had mild TBI were compared with DTI images from 21 veterans with no exposure to TBI during deployment. Conventional voxel-based analysis as well as a method of identifying spatially heterogeneous areas of decreased fractional anisotropy ("potholes") were used. Veterans also underwent psychiatric and neuropsychological assessments.

Results-Voxel-based analysis did not reveal differences in DTI parameters between the veterans with mild TBI and those with no TBI. However, the veterans with mild TBI had a significantly higher number of potholes than those without TBI. The difference in the number of potholes was not influenced by age, time since trauma, a history of mild TBI unrelated to deployment, or coexisting psychopathology. The number of potholes was correlated with the severity of TBI and with performance in executive functioning tasks.

Conclusions-Veterans who had blast-related mild TBI showed evidence of multifocal white matter abnormalities that were associated with severity of the injury and with relevant functional measures. Overall, white matter potholes may constitute a sensitive biomarker of axonal injury that can be identified in mild TBI at acute and chronic stages of its clinical course.

Address correspondence to Dr. Jorge (ricardo-jorge@uiowa.edu).

The other authors report no financial relationships with commercial interests. 
Traumatic brain injury (TBI) has been described as the "signature wound" of the wars in Iraq and Afghanistan. More than 2,000,000 U.S. military personnel have been deployed to those countries since the beginning of the conflicts. It has been estimated that $10 \%-20 \%$ of all veterans of these conflicts experienced mild TBI, with blast injuries being the leading cause (1-5).

The occurrence and severity of TBI are difficult to ascertain in veterans because of retrospective bias in determining relevant clinical variables, such as whether there was loss of consciousness or posttraumatic amnesia. Neuroimaging findings, however, hold promise in providing useful biomarkers for the presence of TBI.

Diffusion tensor imaging (DTI) is a development of MRI that provides objective measures of directional water diffusion in space (e.g., fractional anisotropy), which in white matter regions is essentially determined by the integrity of axonal membranes and myelin sheaths. DTI has been used to detect white matter changes both in the acute and chronic stages of TBI $(6,7)$. DTI abnormalities appear to be graded according to the initial severity of TBI and are negatively correlated with neuropsychological performance (8-11).

The number of studies examining the DTI correlates of blast-related mild TBI is more limited. Mac Donald et al. recently (12) examined diffusion abnormalities occurring in the early stages of mild TBI among soldiers who were evacuated from field operations.

Comparing DTI parameters of 63 soldiers who had experienced mild TBI with those of 21 comparison soldiers who did not have a TBI, they observed that those with mild TBI showed reduced fractional anisotropy in the cerebellar peduncles, cingulate bundles, and orbitofrontal white matter relative to the comparison group. Furthermore, these changes appeared to be persistent in a subgroup $(\mathrm{N}=47)$ of patients who had a follow-up scan 6-12 months later. On the other hand, Levin et al. (13) failed to identify DTI changes among veterans assessed a mean of about 2.4 years after mild TBI. They did, however, find correlations between fractional anisotropy values and neuropsychological performance.

These studies relied on region-of-interest and voxel-based analysis to identify white matter disruption. These methods assume that there is a spatial overlap of lesions across affected subjects, which is not consistent with the multifocal disruption of white matter pathways observed in human studies and experimental models of TBI (14). Davenport et al. (14) addressed this spatial heterogeneity of lesions by analyzing the distribution of fractional anisotropy values across total white matter voxels between Iraq and Afghanistan veterans with and without a history of mild TBI. The number of voxels with low fractional anisotropy (i.e., two or more standard deviations of the control group mean) was greater in the group of veterans exposed to blasts.

In the present study, we used DTI to examine white matter integrity in a relatively large group ( $\mathrm{N}=72)$ of Iraq and Afghanistan veterans with a history of mild TBI. Veterans without a history of TBI ( $\mathrm{N}=21)$ constituted the comparison group. We hypothesized that 1) mild TBI would be associated with a diffuse and heterogeneous pattern of injury; 2) DTI changes would be associated with severity of injury; 3 ) the presence of psychopathology (e.g., posttraumatic stress disorder [PTSD] and alcohol use disorders) would not have an effect on 
DTI findings; and 4) DTI abnormalities would be correlated with alterations in executive functioning.

\section{Method}

\section{Study Group}

The study group consisted of a sample of 93 male veterans of the Iraq and Afghanistan wars recruited at the Iowa City Veterans Affairs (VA) Medical Center. Of the 93 veterans, 72 (77.4\%) had mild TBI related to blast exposure during their deployment. The remaining 21 veterans (22.6\%), who did not experience TBI while deployed, constituted the negative comparison group-veterans unexposed to TBI. Blast injuries were complicated by the effect of acceleration and rotational loadings (tertiary component) in $44.4 \%(\mathrm{~N}=32)$ of the cases. Significant additional body injuries (e.g., bone fractures, burns, and crush injuries) were noted in $13.2 \%(\mathrm{~N}=9)$ of the blast injuries.

A group of 14 patients who experienced mild TBI in civilian settings and were enrolled in an ongoing study at the University of Iowa constituted a positive control group-civilians exposed to TBI. These patients had DTI within 90 days after their trauma. The presence of psychopathology was an exclusion criterion for enrollment in this study. Participants in the civilian TBI group had injuries that were considered mild according to conventional severity measures (i.e., Glasgow Coma Scores from 13 to 15). Furthermore, they had no identifiable lesions in their delayed research MRI scan (e.g., hemosiderin deposits or dilated perivascular spaces). They had been admitted to the hospital for various reasons, such as incomplete resolution of post-traumatic amnesia in the first few hours after TBI and the presence of associated facial or orthopedic injuries that required specialized evaluation and treatment. In half of these patients $(\mathrm{N}=7)$, a review of their admission CT scans revealed the presence of subtle alterations-mild edema, isolated punctate contusions (less than $1.5 \mathrm{~mm}$ in diameter), or small extracerebral collections. This suggests that some of the civilians may have had more severe injuries than the veterans, but because we do not have acute CT scans for the latter, this supposition cannot be confirmed.

The Mayo Clinic Classification guidelines (15) were used to categorize mild TBI into two categories: probable and possible mild TBI. Probable mild TBI was diagnosed in 29 (27.1\%) veterans when there was evidence of loss of consciousness lasting less than 30 minutes or evidence of posttraumatic amnesia lasting more than 30 minutes and less than 24 hours. A total of $43(40.2 \%)$ veterans who reported the presence of vague symptoms of confusion and dazedness lasting more than a few minutes after exposure were diagnosed as having possible mild TBI $(15,16)$.

\section{Neuropsychiatric and Neuropsychological Assessments}

Psychiatric assessment included the Mini-International Neuropsychiatric Interview (17), the Clinician-Administered PTSD Scale (CAPS) (18), the Hamilton Depression Rating Scale (HAM-D) (19), and the Alcohol Use Disorders Identification Test (AUDIT) (20).

Neuropsychological assessment consisted of the Wechsler Test of Adult Reading (21), the California Verbal Learning Test-II (22), the Brief Visuospatial Memory Test-Revised (23), 
the Trail Making Test, Part B (24), the Grooved Pegboard Test (25), the Ruff $2 \& 7$ Test (26), and the Digit Span Test (27).

Given that TBI is selectively associated with alterations in executive and memory functions, and in order to limit the number of comparisons in our analysis, we collapsed the results of the tests into an executive and a memory domain. (For further details, see the data supplement that accompanies the online edition of this article.)

\section{Neuroimaging and Image Analysis}

MR imaging was conducted on a Siemens TIM Trio scanner and included $T_{1}, T_{2}$, fluidattenuated inversion recovery, $\mathrm{T}_{2}{ }^{*}$, and DTI sequences (for further details, see the online data supplement).

Quality assurance of DTI was performed using DTIPrep (28). Diffusion gradient volumes identified with artifacts were removed and the remaining high-quality diffusion-weighted images retained. We used two approaches to analyze the DTI data: voxel-based analysis and pothole analysis. Voxel-based analysis of fractional anisotropy data across subjects was performed using tract-based spatial statistics (29).

"Potholes" are small regions of the white matter that have abnormally low fractional anisotropy compared with what is expected based on the control population. The method for identifying potholes has been described elsewhere (30). In brief, the analysis of the fractional anisotropy images of all subjects in the comparison population was used to create an average and a standard deviation image. These statistical images were used to create a zscore image for each subject, in which the fractional anisotropy value for every voxel was converted to a z-score based on the mean and standard deviation from the comparison group. To find potholes, each subject's z-score image was then thresholded at -3.00 , and an algorithm labeled the contiguous voxels below this threshold. The sum of potholes of all sizes constituted the measure of white matter disruption.

\section{Statistical Analysis}

We report means and SDs for continuous measures. Wilcoxon rank sum or Kruskal-Wallis tests were used when data did not conform to the statistical assumptions of the $t$ test or analysis of variance, respectively. Categorical data were analyzed using Fisher's exact test.

We used multiple linear regression models to assess the association between TBI and the number of potholes in the brain after controlling for age, time since trauma, number of blast episodes, HAM-D score, and CAPS score. The possible confounders were selected from among the characteristics that were different between the groups. (For further details, see the online data supplement.)

We also computed Spearman correlations between the number of potholes in the corpus callosum and the neuropsychological domain scores mentioned in the previous section. The corpus callosum was selected for two reasons: because it is a structure that is selectively involved in traumatic axonal injury, and because there is evidence that alterations of DTI parameters of this structure are associated with cognitive functioning (31-34). Age, 
education, time since trauma, and severity of PTSD symptoms were selected as covariates in these regression models.

\section{Results}

The demographic and clinical characteristics of the unexposed veterans, veterans with possible TBI, and veterans with probable TBI are summarized in Table 1. Veterans with probable TBI had more education on average than those with possible TBI (Wilcoxon statistic $=1,283.5, \mathrm{p}=0.009$ ). Time since returning from deployment was shorter on average for the veterans unexposed to TBI compared with time since trauma for the possible and probable TBI groups (Wilcoxon statistic $=442, \mathrm{p}=0.001$, and Wilcoxon statistic $=388$, $\mathrm{p}=0.008$, respectively). Participants with possible TBI had more blast episodes than the unexposed and probable TBI groups (Wilcoxon statistic $=262.5, \mathrm{p}, 0.0001$, and Wilcoxon statistic $=1,234.5, \mathrm{p}=0.04$, respectively).

\section{Voxel-Based Analysis}

When controlling for multiple comparisons, tract-based spatial statistics analysis of the skeletonized white matter tracts revealed no differences in fractional anisotropy and mean diffusivity across the groups. These findings are consistent with those observed in previous studies of veterans of the Iraq and Afghanistan wars (13).

\section{Pothole Analysis}

Taking into account that the negative findings obtained through voxel-based analysis can be attributed to the spatial heterogeneity of white matter lesions (14), we compared the total number of potholes at a z-score threshold of -3 (Figure 1). The three groups differed significantly in the total number of potholes (Kruskal-Wallis $\chi^{2}=46.2, \mathrm{df}=2, \mathrm{p}<0.0001$ ). Specifically, the number of potholes was higher in veterans with probable TBI (mean=98.8, $\mathrm{SD}=56.1$; Wilcoxon $\mathrm{p}<0.0001$ ) and those with possible $\mathrm{TBI}$ (mean=95.3, $\mathrm{SD}=48.7)$ than the unexposed veterans (mean=16.8, $\mathrm{SD}=10.5$; Wilcoxon $\mathrm{p}<0.0001$ ) (Figure 2).

To further investigate the differences in number of potholes between the three groups, we used a normal regression model with the log-transformed number of potholes as the dependent variable and TBI group and all the variables that differed between the groups as independent variables. Because the presence of PTSD, mood disturbance, and alcohol misuse might be associated with alterations in white matter tracts, we also investigated the effect of HAM-D, CAPS, and AUDIT scores on total number of potholes. After controlling for these possible confounders, the difference between groups remained significant ( $\mathrm{F}=17.7$, $\mathrm{df}=2,80, \mathrm{p}<0.0001$ ). None of the possible confounders were significant predictors of the number of potholes. Excluding participants who had a TBI before deployment did not affect these results.

Once we had established an association between the presence of potholes and mild TBI, we examined whether similar white matter alterations could be observed in patients who experienced TBI in civilian settings. 
Since we found no evidence of any difference in number of potholes between the possible and probable mild TBI groups, we collapsed the two groups into one (veterans with TBI, $\mathrm{N}=72$ ) for further comparisons. Table 2 summarizes the demographic and clinical characteristics of the unexposed veterans, veterans with TBI, and civilians with TBI.

The civilians with TBI were older on average than the veterans with TBI (Wilcoxon statistic $=840.5, \mathrm{p}<0.007$ ) and had shorter time since trauma (Wilcoxon statistic=105, $\mathrm{p}<0.0001)$.

We found that total number of potholes was significantly different between the three groups (Figure 1) (Kruskal-Wallis $\chi^{2}=54.3, \mathrm{df}=2, \mathrm{p}<0.0001$ ). The civilian TBI group had more potholes than the veteran TBI and unexposed veteran groups (civilian TBI group, mean=148.6 [SD=66.0]; veteran TBI group, mean=96.7 [SD=51.4]; unexposed veteran group, mean=16.8 [SD=10.5]; Wilcoxon statistic $=865, \mathrm{p}=0.004$, and Wilcoxon statistic $=399, \mathrm{p}<0.0001$, respectively). Also, veterans with TBI had more potholes on average than unexposed veterans (Wilcoxon statistic $=247.5$, $\mathrm{p}<0.0001$ ). After controlling for age, time since trauma, HAM-D score, and CAPS score, the difference between groups remained $(\mathrm{F}=70.5, \mathrm{df}=2,89, \mathrm{p}<0.0001)$. Excluding participants who had experienced a TBI before deployment or, in the case of civilians, before the current TBI did not affect these results.

We then examined whether number of potholes was associated with TBI severity, which we defined in terms of duration of posttraumatic amnesia using an ordinal scale (see the online data supplement). Overall, number of potholes was positively associated with TBI severity (Spearman's rho $=0.58, \mathrm{p}<0.0001, \mathrm{~N}=106$ ). In addition, Glasgow Coma Scale scores (available only for the civilian group) were inversely associated with the total number of potholes (Spearman's rho $=-0.58, \mathrm{p}=0.03, \mathrm{~N}=14$ ). Furthermore, patients who experienced loss of consciousness at the time of the trauma had a greater number of potholes than those who did not (Wilcoxon statistic=2,360.5, $\mathrm{p}=0.0007, \mathrm{~N}=107$ ).

Finally, to investigate the functional correlates of these white matter abnormalities, we examined whether number of potholes was associated with neuropsychological performance among the veteran groups. We observed a negative correlation between the number of potholes in the corpus callosum and performance in the executive domain (Spearman's rho= $-0.23, \mathrm{p}=0.03$ ). This association persisted when the analysis controlled for relevant variables such as age, education, time since trauma, and severity of PTSD symptoms.

\section{Discussion}

To our knowledge, this is the largest study in which DTI was used to examine the integrity of white matter pathways among veterans of the Iraq and Afghanistan wars who sustained mild TBI during their deployment. Voxel-based analysis did not demonstrate any differences between veterans with a history of mild TBI and those without exposure to TBI during deployment. However, several years after the trauma, veterans with a history of mild TBI had a higher number of diffusely distributed areas of decreased fractional anisotropy (potholes) than did veterans who did not experience TBI. Potholes were also observed in 
patients who experienced mild TBI in civilian settings and were examined within 90 days after the trauma. The difference between groups in number of potholes was not influenced by age, time since trauma, history of mild TBI unrelated to deployment, presence of mood or anxiety disorders, or antecedent alcohol misuse. Number of potholes was correlated with severity of TBI and with performance on executive functioning tasks.

The limitations of this study are related to the difficulty in making retrospective TBI diagnoses in veterans, particularly those with concurrent PTSD. It might be argued that selection of veterans without psychiatric comorbidity would reduce this variability. However, excluding subjects with these conditions would result in an unrepresentative sample of this population. In fact, time since trauma and coexisting psychopathology or alcohol misuse did not affect the results. Our findings, however, are applicablemainly to the group of symptomatic patients who are followed in polytrauma services in the VA system.

The failure to detect white matter abnormalities using voxel-based analysis replicates the findings of other studies of veterans of the Iraq and Afghanistan wars $(13,14)$. The fact that DTI metrics were abnormal in the initial phase of mild TBI suggests the possibility that DTI abnormalities normalize with time. The available literature on civilian TBI shows that in the chronic stage, fractional anisotropy is persistently reduced in some white matter areas, while other areas show an increase in fractional anisotropy that is suggestive of axonal recovery. The extent of this regeneration process would influence the functional outcome of these patients (35). This complex process of damage and repair probably also occurs in military mild TBI.

Discrepant voxel-based analysis findings in civilian and military samples may be related to the fact that the mechanism producing brain damage in blast injuries is different from the mechanisms involved in civilian TBI (36). For instance, the vascular load produced by blast overpressure is an important etiological factor in blast injuries that plays no role in civilian injuries $(37,38)$, while the inertial loadings that produce axonal injury in civilian TBI may be less important in blast TBI (39). These biophysical differences may determine the size and spatial distribution of brain lesions as well as the timing of pathological events, such as the disruption of the blood-brain barrier and cerebral vasospasm $(36,40,41)$. For instance, axonal damage in blast injuries may be more marked in brainstem and cerebellar pathways $(12,42)$.

In spite of the negative voxel-based analysis findings, veterans with mild TBI had a significantly greater number of potholes than those without TBI. The fact that potholes are observed more frequently in veterans with a history of mild TBI suggests that they are not an artifact resulting from the processing of DTI images. Consistently, potholes were observed with a greater frequency in a positive control group (civilians with mild TBI) than in a group of veterans with TBI or in a group of unexposed veterans. The incremental pattern in the number of potholes of these groups (Figure 1) may be related to several factors. For instance, given that all the civilian participants with TBI were admitted to the hospital, they may have had more severe injuries. In addition, they were assessed earlier in their clinical course, when repair processes would not have been completed. 
On the other hand, we did not find a difference in number of potholes between patients with probable TBI and those with possible TBI. This finding underscores the effect of retrospective bias in ascertaining TBI in the veteran population. Veterans often do not accurately recall the blast event and may overestimate or underestimate its consequences (43). Although veterans in the possible TBI group experienced a greater number of blasts than those with probable TBI, we did not observe an effect of the number of injuries on the number of potholes that would suggest cumulative axonal pathology. Thus, we believe that retrospective bias is the major factor behind the lack of significant differences between the probable and possible TBI groups.

If potholes are related to traumatic axonal injury, we would expect a positive correlation between their number and the severity of TBI. We found that number of potholes was associated with a history of loss of consciousness and with duration of posttraumatic amnesia. Furthermore, we obtained similar results when analyzing Glasgow Coma Scale scores in the civilian group.

Finally, we found that the number of potholes in the corpus callosum was negatively correlated with performance in executive functioning tasks. DTI abnormalities of the corpus callosum have been consistently associated with the cognitive outcome of TBI $(31-33,44)$. Moreover, a recent study of veterans of the Iraq and Afghanistan wars found that soldiers with mild TBI had decreased interhemispheric coordination of brain activity, an effect that is probably related to damage to the anterior corpus callosum(34). The association between number of potholes in the corpus callosum and performance on cognitive tasks remained significant independently of the effect attributable to the severity of PTSD symptoms, a major factor contributing to executive dysfunction among veterans of the Iraq and Afghanistan wars (45).

White matter potholes may constitute a biomarker of axonal injury that can be identified in mild TBI at both the acute and chronic stages of its clinical course. They are associated with the severity of the injury and with relevant functional outcomes. Furthermore, pothole analysis may be more sensitive than conventional neuroimaging approaches given its ability to detect diffuse and spatially nonoverlapping defects. Future studies will need to replicate these findings in other groups of TBI patients with different etiologies and severity, delineate the longitudinal course of DTI abnormalities, and analyze the effect of repetitive mild TBI.

\section{Supplementary Material}

Refer to Web version on PubMed Central for supplementary material.

\section{Acknowledgments}

Dr. Jorge has served as a consultant to Avanir Pharmaceuticals. Mr. Pierson is owner of Brain Image Analysis, LLC. Dr. Crespo-Facorro has served as a speaker at educational events for Pfizer, Bristol-Myers Squibb, and Johnson \& Johnson and has served on advisory boards for Eli Lilly.

Supported by VA Merit Research Award D7201I to Dr. Jorge. 


\section{References}

1. Galarneau MR, Woodruff SI, Dye JL, Mohrle CR, Wade AL. Traumatic brain injury during Operation Iraqi Freedom: findings from the United States Navy-Marine Corps Combat Trauma Registry. J Neurosurg. 2008; 108:950-957. [PubMed: 18447712]

2. Wade AL, Dye JL, Mohrle CR, Galarneau MR. Head, face, and neck injuries during Operation Iraqi Freedom II: results from the US Navy-Marine Corps Combat Trauma Registry. J Trauma. 2007; 63:836-840. [PubMed: 18090014]

3. Sayer NA, Cifu DX, McNamee S, Chiros CE, Sigford BJ, Scott S, Lew HL. Rehabilitation needs of combat-injured service members admitted to the VA Polytrauma Rehabilitation Centers: the role of PM\&R in the care of wounded warriors. PM R. 2009; 1:23-28. [PubMed: 19627869]

4. Schneiderman AI, Braver ER, Kang HK. Understanding sequelae of injury mechanisms and mild traumatic brain injury incurred during the conflicts in Iraq and Afghanistan: persistent postconcussive symptoms and posttraumatic stress disorder. Am J Epidemiol. 2008; 167:1446-1452. [PubMed: 18424429]

5. Terrio H, Brenner LA, Ivins BJ, Cho JM, Helmick K, Schwab K, Scally K, Bretthauer R, Warden D. Traumatic brain injury screening: preliminary findings in a US Army Brigade Combat Team. J Head Trauma Rehabil. 2009; 24:14-23. [PubMed: 19158592]

6. Chu Z, Wilde EA, Hunter JV, McCauley SR, Bigler ED, Troyanskaya M, Yallampalli R, Chia JM, Levin HS. Voxel-based analysis of diffusion tensor imaging in mild traumatic brain injury in adolescents. AJNR Am J Neuroradiol. 2010; 31:340-346. [PubMed: 19959772]

7. Mayer AR, Ling J, Mannell MV, Gasparovic C, Phillips JP, Doezema D, Reichard R, Yeo RA. A prospective diffusion tensor imaging study in mild traumatic brain injury. Neurology. 2010; 74:643-650. [PubMed: 20089939]

8. Huang MX, Theilmann RJ, Robb A, Angeles A, Nichols S, Drake A, D’Andrea J, Levy M, Holland M, Song T, Ge S, Hwang E, Yoo K, Cui L, Baker DG, Trauner D, Coimbra R, Lee RR. Integrated imaging approach with MEG and DTI to detect mild traumatic brain injury in military and civilian patients. J Neurotrauma. 2009; 26:1213-1226. [PubMed: 19385722]

9. Lipton ML, Gellella E, Lo C, Gold T, Ardekani BA, Shifteh K, Bello JA, Branch CA. Multifocal white matter ultrastructural abnormalities in mild traumatic brain injury with cognitive disability: a voxel-wise analysis of diffusion tensor imaging. J Neurotrauma. 2008; 25:1335-1342. [PubMed: 19061376]

10. Salmond CH, Menon DK, Chatfield DA, Williams GB, Pena A, Sahakian BJ, Pickard JD. Diffusion tensor imaging in chronic head injury survivors: correlations with learning and memory indices. Neuroimage. 2006; 29:117-124. [PubMed: 16084738]

11. Kraus MF, Susmaras T, Caughlin BP, Walker CJ, Sweeney JA, Little DM. White matter integrity and cognition in chronic traumatic brain injury: a diffusion tensor imaging study. Brain. 2007; 130(Pt 10):2508-2519. [PubMed: 17872928]

12. Mac Donald CL, Johnson AM, Cooper D, Nelson EC, Werner NJ, Shimony JS, Snyder AZ, Raichle ME, Witherow JR, Fang R, Flaherty SF, Brody DL. Detection of blast-related traumatic brain injury in US military personnel. N Engl J Med. 2011; 364:2091-2100. [PubMed: 21631321]

13. Levin HS, Wilde E, Troyanskaya M, Petersen NJ, Scheibel R, Newsome M, Radaideh M, Wu T, Yallampalli R, Chu Z, Li X. Diffusion tensor imaging of mild to moderate blast-related traumatic brain injury and its sequelae. J Neurotrauma. 2010; 27:683-694. [PubMed: 20088647]

14. Davenport ND, Lim KO, Armstrong MT, Sponheim SR. Diffuse and spatially variable white matter disruptions are associated with blast-related mild traumatic brain injury. Neuroimage. 2012; 59:2017-2024. [PubMed: 22040736]

15. Malec JF, Brown AW, Leibson CL, Flaada JT, Mandrekar JN, Diehl NN, Perkins PK. The Mayo classification system for traumatic brain injury severity. J Neurotrauma. 2007; 24:1417-1424. [PubMed: 17892404]

16. Hoge CW, McGurk D, Thomas JL, Cox AL, Engel CC, Castro CA. Mild traumatic brain injury in US soldiers returning from Iraq. N Engl J Med. 2008; 358:453-463. [PubMed: 18234750]

17. Sheehan DV, Lecrubier Y, Sheehan KH, Amorim P, Janavs J, Weiller E, Hergueta T, Baker R, Dunbar GC. The Mini-International Neuropsychiatric Interview (MINI): the development and 
validation of a structured diagnostic psychiatric interview for DSM-IV and ICD-10. J Clin Psychiatry. 1998; 59(Suppl 20):22-33. [PubMed: 9881538]

18. Blake DD, Weathers FW, Nagy LM, Kaloupek DG, Gusman FD, Charney DS, Keane TM. The development of a Clinician-Administered PTSD Scale. J Trauma Stress. 1995; 8:75-90. [PubMed: 7712061]

19. Hamilton M. The assessment of anxiety states by rating. Br J Med Psychol. 1959; 32:50-55. [PubMed: 13638508]

20. Babor, TF.; Higgins-Biddle, JC.; Saunders, JB.; Monteiro, MG. The Alcohol Use Disorders Identification Test: Guidelines for Use in Primary Care. 2nd ed. Geneva: World Health Organization; 2001.

21. Wechsler, D. Wechsler Test of Adult Reading. New York: Psychological Corporation; 2001.

22. Alexander MP, Stuss DT, Fansabedian N. California Verbal Learning Test: performance by patients with focal frontal and non-frontal lesions. Brain. 2003; 126:1493-1503. [PubMed: $12764068]$

23. Benedict, RHB. Brief Visuospatial Memory Test-Revised. Odessa, Fla: Psychological Assessment Resources; 1997.

24. Reitan RM. Trail Making Test results for normal and brain-damaged children. Percept Mot Skills. 1971; 33:575-581. [PubMed: 5124116]

25. Matthews, CG.; Klove, H. Instruction Manual for the Adult Neuropsychology Test Battery. Madison: University of Wisconsin Medical School; 1964.

26. Allen, RMRCC. Ruff 2 and 7 Selective Attention Test Professional Manual. Odessa, Fla: Psychological Assessment Resources; 1996.

27. Wechsler, D. Manual for the Wechsler Adult Intelligence Scale-Revised. New York: Psychological Corp; 1981.

28. Liu, Z.; Wang, Y.; Gerig, G.; Gouttard, S.; Tao, R.; Fletcher, T.; Styner, M. Quality control of diffusion weighted images, in Medical Imaging 2010: Advanced PACS-based Imaging Informatics and Therapeutic Applications. In: Liu, BJ.; Boonn, WW., editors. Proceedings of the SPIE. Vol. 7628. 2010. 76280J-76280J-9

29. Smith SM, Jenkinson M, Johansen-Berg H, Rueckert D, Nichols TE, Mackay CE, Watkins KE, Ciccarelli O, Cader MZ, Matthews PM, Behrens TE. Tract-based spatial statistics: voxelwise analysis of multi-subject diffusion data. Neuroimage. 2006; 31:1487-1505. [PubMed: 16624579]

30. White T, Schmidt M, Karatekin C. White matter "potholes" in early-onset schizophrenia: a new approach to evaluate white matter microstructure using diffusion tensor imaging. Psychiatry Res. 2009; 174:110-115. [PubMed: 19853414]

31. Rutgers DR, Fillard P, Paradot G, Tadié M, Lasjaunias P, Ducreux D. Diffusion tensor imaging characteristics of the corpus callosum in mild, moderate, and severe traumatic brain injury. AJNR Am J Neuroradiol. 2008; 29:1730-1735. [PubMed: 18617586]

32. Wilde EA, Chu Z, Bigler ED, Hunter JV, Fearing MA, Hanten G, Newsome MR, Scheibel RS, Li $\mathrm{X}$, Levin HS. Diffusion tensor imaging in the corpus callosum in children after moderate to severe traumatic brain injury. J Neurotrauma. 2006; 23:1412-1426. [PubMed: 17020479]

33. Kumar R, Husain M, Gupta RK, Hasan KM, Haris M, Agarwal AK, Pandey CM, Narayana PA. Serial changes in the white matter diffusion tensor imaging metrics in moderate traumatic brain injury and correlation with neuro-cognitive function. J Neurotrauma. 2009; 26:481-495. [PubMed: 19196176]

34. Sponheim SR, McGuire KA, Kang SS, Davenport ND, Aviyente S, Bernat EM, Lim KO. Evidence of disrupted functional connectivity in the brain after combat-related blast injury. Neuroimage. 2011; 54(Suppl 1):S21-S29. [PubMed: 20851190]

35. Sidaros A, Engberg AW, Sidaros K, Liptrot MG, Herning M, Petersen P, Paulson OB, Jernigan TL, Rostrup 1E. Diffusion tensor imaging during recovery from severe traumatic brain injury and relation to clinical outcome: a longitudinal study. Brain. 2008; 131:559-572. [PubMed: 18083753]

36. Cernak I, Noble-Haeusslein LJ. Traumatic brain injury: an overview of pathobiology with emphasis on military populations. J Cereb Blood Flow Metab. 2010; 30:255-266. [PubMed: 19809467] 
37. Courtney AC, Courtney MW. A thoracic mechanism of mild traumatic brain injury due to blast pressure waves. Med Hypotheses. 2009; 72:76-83. [PubMed: 18829180]

38. Long JB, Bentley TL, Wessner KA, Cerone C, Sweeney S, Bauman RA. Blast overpressure in rats: recreating a battlefield injury in the laboratory. J Neurotrauma. 2009; 26:827-840. [PubMed: 19397422]

39. Povlishock JT, Katz DI. Update of neuropathology and neurological recovery after traumatic brain injury. J Head Trauma Rehabil. 2005; 20:76-94. [PubMed: 15668572]

40. Ling G, Bandak F, Armonda R, Grant G, Ecklund J. Explosive blast neurotrauma. J Neurotrauma. 2009; 26:815-825. [PubMed: 19397423]

41. Bauman RA, Ling G, Tong L, Januszkiewicz A, Agoston D, Delanerolle N, Kim Y, Ritzel D, Bell R, Ecklund J, Armonda R, Bandak F, Parks S. An introductory characterization of a combatcasualty-care relevant swine model of closed head injury resulting from exposure to explosive blast. J Neurotrauma. 2009; 26:841-860. [PubMed: 19215189]

42. Garman RH, Jenkins LW, Switzer RC 3rd, Bauman RA, Tong LC, Swauger PV, Parks SA, Ritzel DV, Dixon CE, Clark RS, Bayir H, Kagan V, Jackson EK, Kochanek PM. Blast exposure in rats with body shielding is characterized primarily by diffuse axonal injury. J Neurotrauma. 2011; 28:947-959. [PubMed: 21449683]

43. Miller G. The invisible wounds of war: healing the brain, healing the mind. Science. 2011; 333:514-517. [PubMed: 21798909]

44. Levin HS, Wilde EA, Hanten G, Li X, Chu ZD, Vásquez AC, Cook L, Yallampalli R, Hunter JV. Mental state attributions and diffusion tensor imaging after traumatic brain injury in children. Dev Neuropsychol. 2011; 36:273-287. [PubMed: 21462007]

45. Vasterling JJ, Verfaellie M, Sullivan KD. Mild traumatic brain injury and posttraumatic stress disorder in returning veterans: perspectives from cognitive neuroscience. Clin Psychol Rev. 2009; 29:674-684. [PubMed: 19744760] 

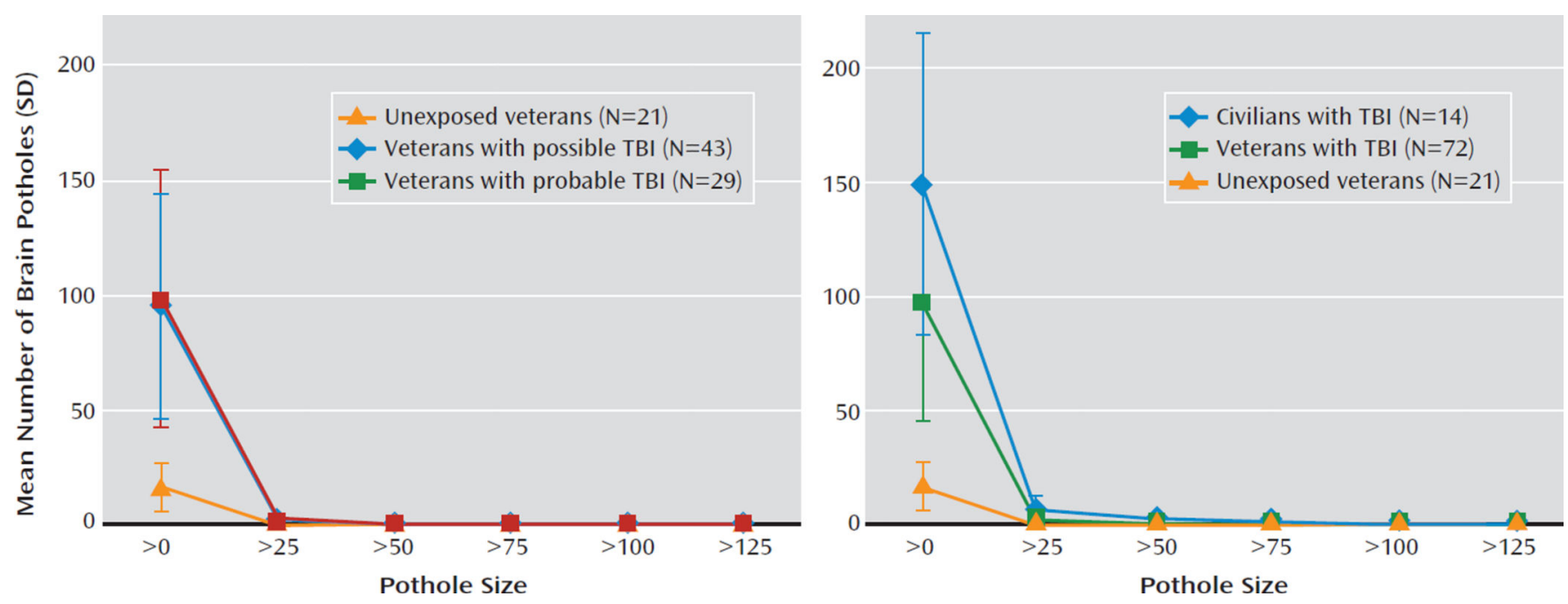

FIGURE 1.

Total Number of White Matter Regions With Abnormally Low Fractional Anisotropy (Potholes) in Veterans With Possible Traumatic Brain Injury (TBI), Probable TBI, and No Exposure to TBI and in Civilians with TBIa

a Analyses compared the total number of potholes at a $\mathrm{z}$-score threshold of -3 . Total number of potholes differed significantly between unexposed veterans, veterans with possible TBI, and veterans with probable TBI (Kruskal-Wallis $\chi^{2}=46.2, \mathrm{df}=2, \mathrm{p}<0.0001$ ) and between civilians with TBI, veterans with TBI, and unexposed veterans (Kruskal-Wallis $\chi^{2}=54.3$, $\mathrm{df}=2, \mathrm{p}<0.0001)$. 
Unexposed Veterans
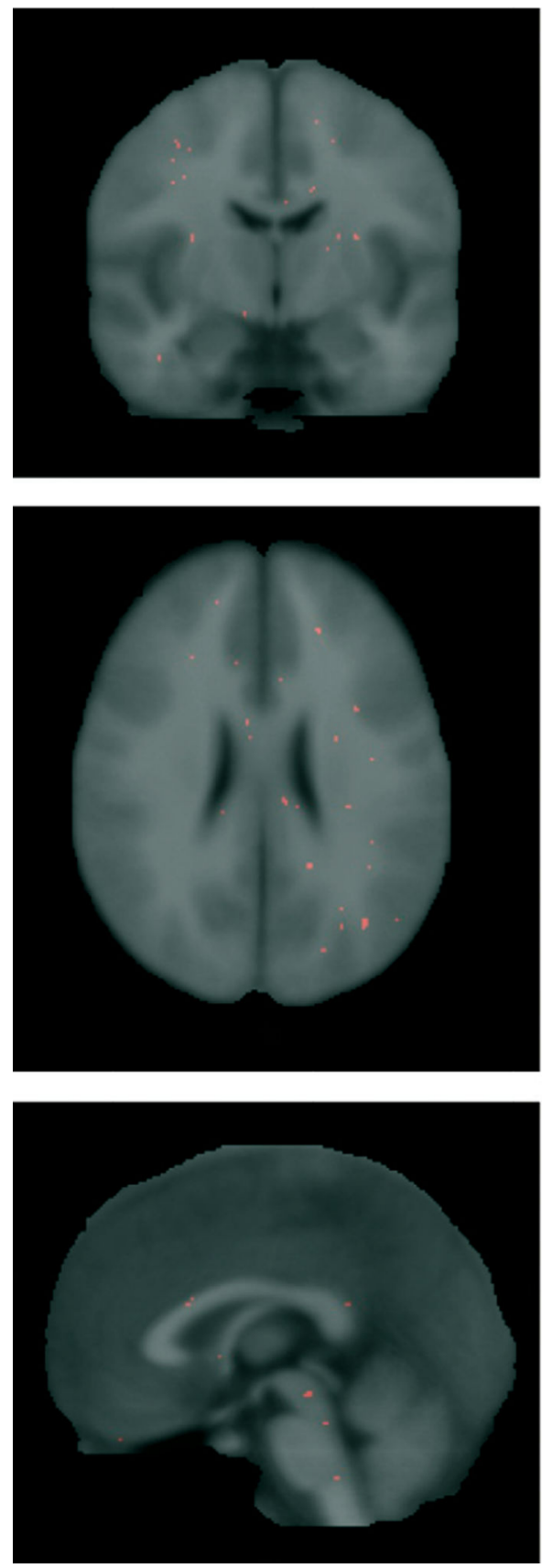

Veterans With Possible TBI
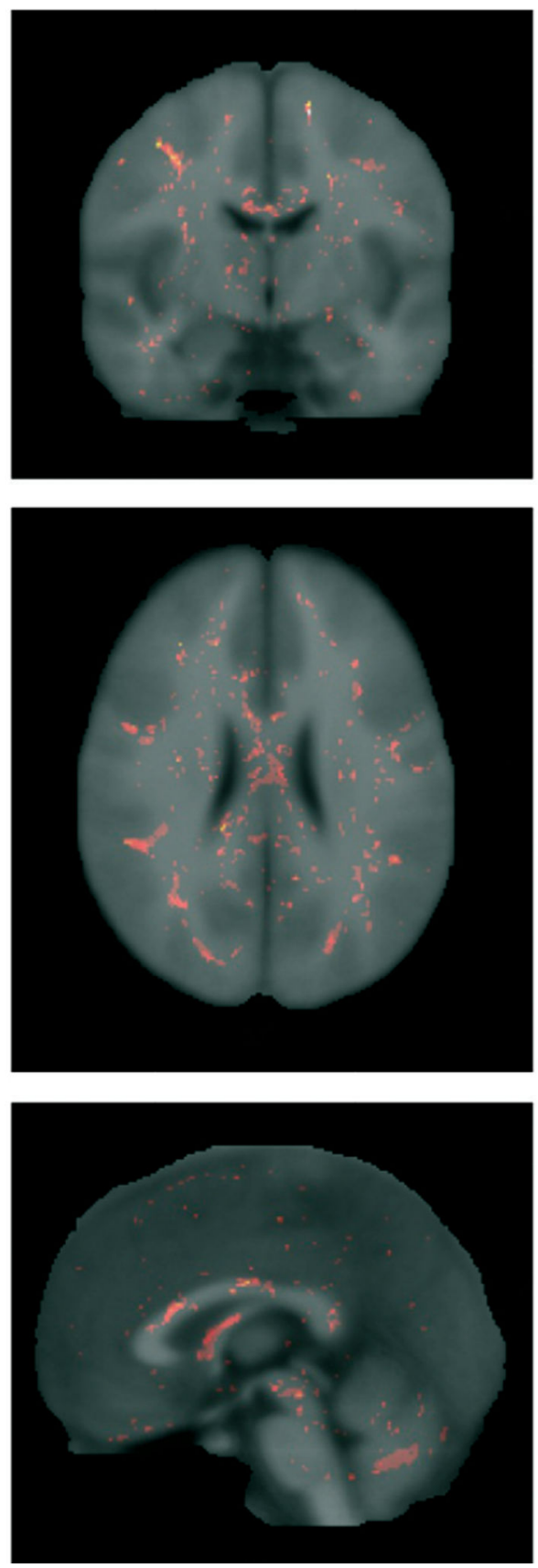

Veterans With Probable TBI
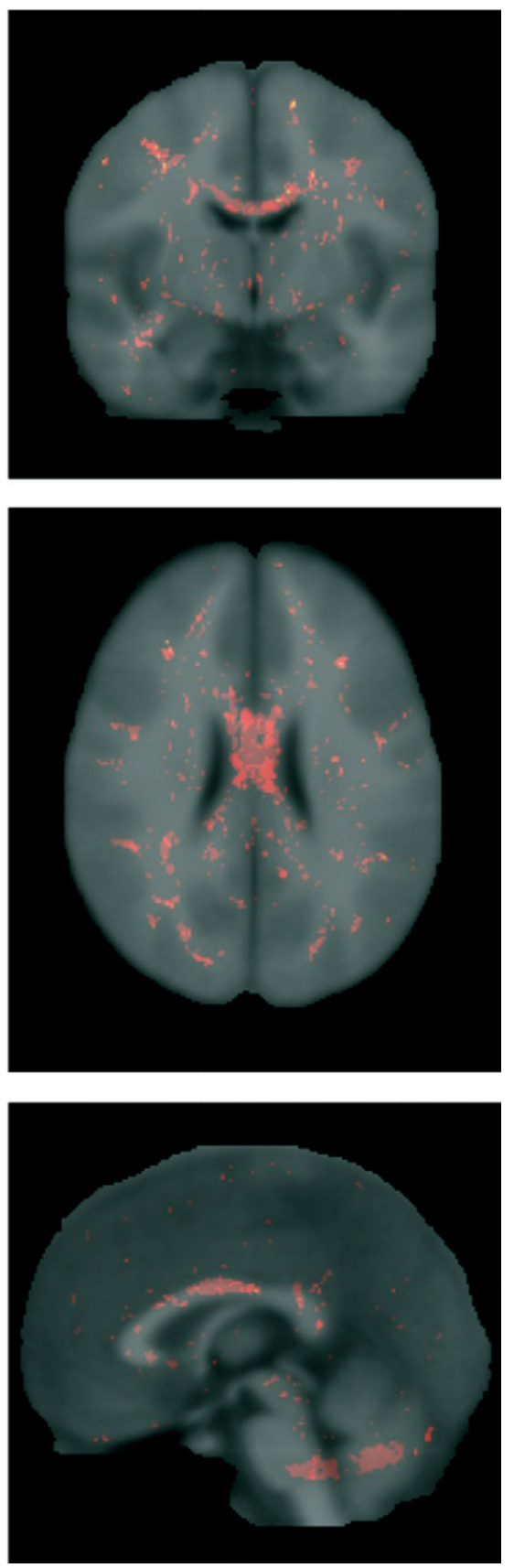

FIGURE 2.

Composite Illustrations of White Matter Regions With Abnormally Low Fractional Anisotropy (Potholes) in Veterans With Possible Traumatic Brain Injury (TBI), Probable TBI, and No Exposure to TBIa

${ }^{\mathrm{a}} \mathrm{Z}$-Score images were thresholded at -3.0. Overlap of potholes across subjects is represented by darker shades of red and yellow. 


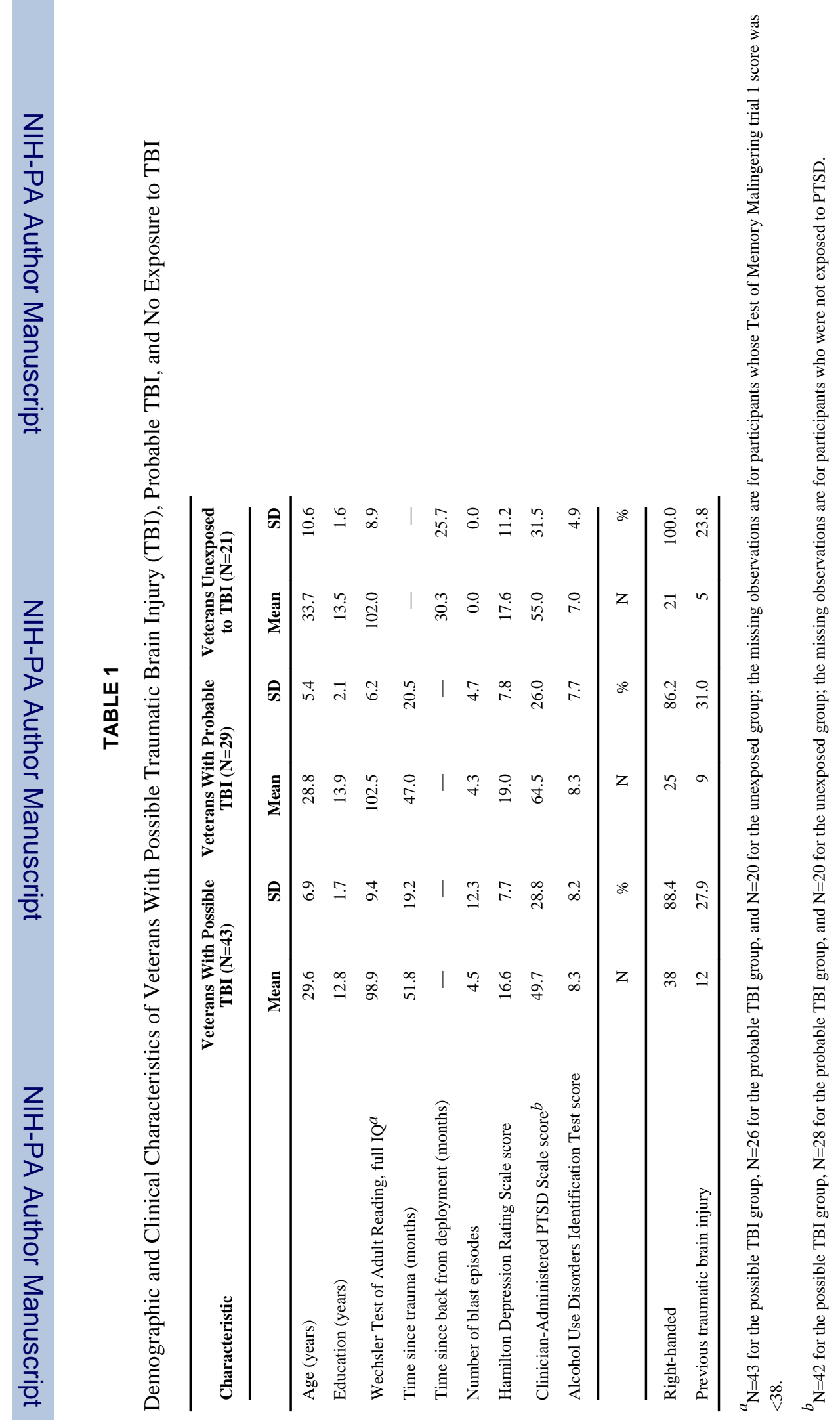




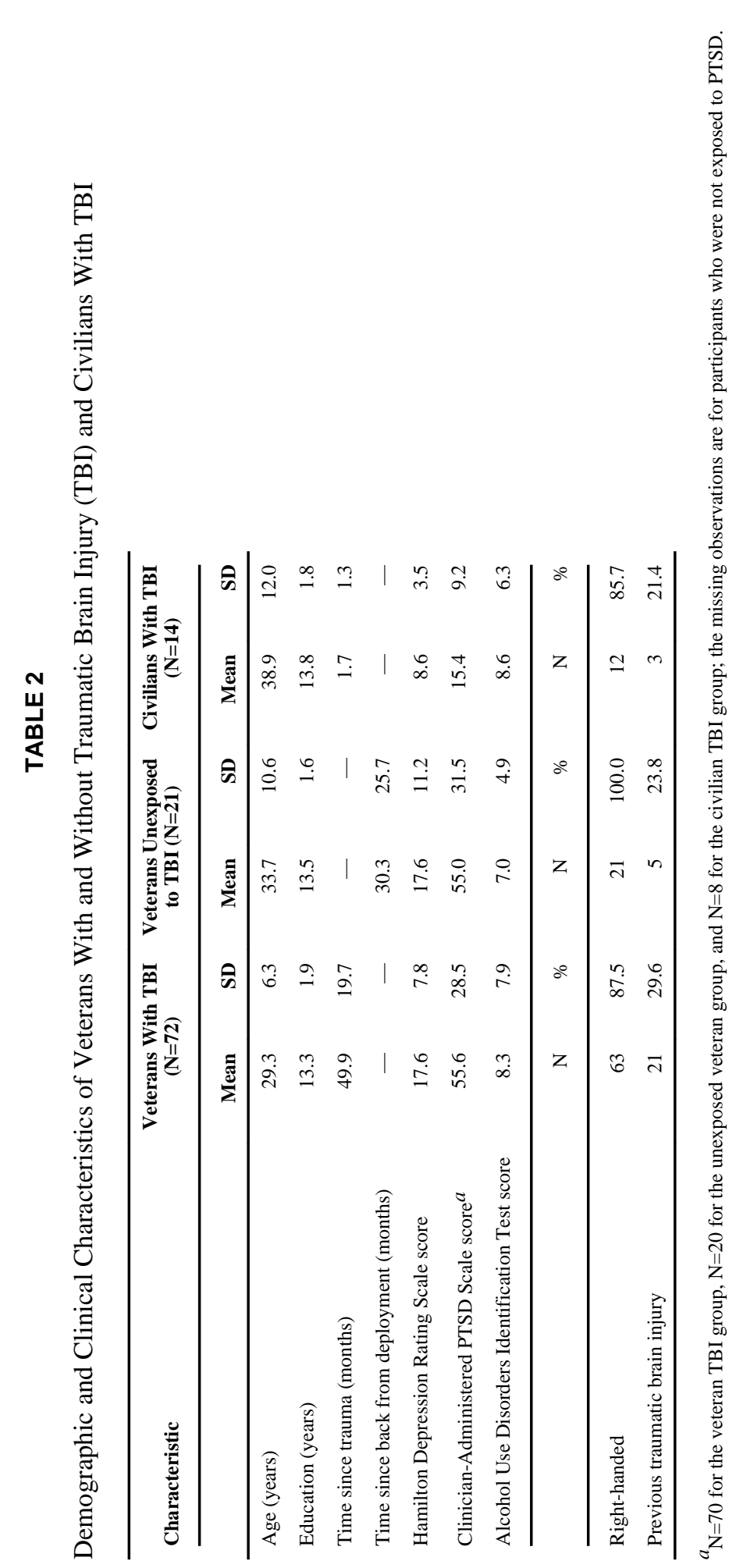

